\title{
Water and beverage consumption patterns among 4 to 13-year-old children in the United Kingdom
}

\author{
Florent Vieux ${ }^{1}$, Matthieu Maillot', Florence Constant ${ }^{2}$ and Adam Drewnowski ${ }^{3 *}$
}

\begin{abstract}
Background: The UK government has announced a tax on sugar-sweetened beverages. The aim of this study was to assess consumption patterns for plain drinking water relative to sugary beverages among UK children.

Methods: Dietary intake data for 845 children aged 4-13 years came from the nationally representative cross-sectional National Diet and Nutrition Survey, 2008-2011. Beverage categories were drinking water (tap or bottled), milk, 100\% fruit juices, soda, fruit drinks, tea, coffee, sports drinks, flavored waters, and liquid supplements. Consumption patterns were examined by age group, gender, household incomes, time and location of consumption, region and seasonality. Total water consumption from drinking water, beverages, and foods, and the water-to-calorie ratios (L/kcal) were compared to the EFSA (European Food Safety Authority) adequate intake standards.

Results: Total water intake (1338 ml/d) came from plain water (19\%), beverages (48\%), and food moisture (33\%). Plain drinking water provided $258 \mathrm{~g} / \mathrm{d}$ (241 g/d for children aged 4-8 years; $274 \mathrm{~g} / \mathrm{d}$ for 9-13 years), mostly (83.8\%) from tap. Water and beverages supplied $901 \mathrm{~g} / \mathrm{d}$ of water. Tap water consumption increased with income and was highest in the South of England. The consumption of bottled water, soda, tea and coffee increased with age, whereas milk consumption declined. About $88.7 \%$ of children did not meet EFSA adequate intake standards. The daily water shortfall ranged from $322 \mathrm{ml} / \mathrm{d}$ to $659 \mathrm{ml} / \mathrm{d}$. Water-to-calorie ratio was $0.845 \mathrm{~L} / 1000 \mathrm{kcal}$ short of desirable levels of $1.0-1.5 \mathrm{~L} / 1000 \mathrm{kcal}$.
\end{abstract}

Conclusion: Total water intake were at $74.8 \%$ of EFSA reference values. Drinking water consumption among children in the UK was well below US and French estimates.

Keywords: Water, tap and bottled, Beverages, Consumption patterns, Children, Adequate water intake, EFSA recommendation

\section{Background}

Water requirements to meet hydration needs are usually supplied by plain drinking water, water from beverages, and by moisture from food [1-3]. Water and beverages generally supply $65-75 \%$ of total water, whereas food moisture supplies $25-35 \%$, depending on eating habits and age $[4,5]$. Water consumption patterns can be further influenced by cultural habits and by access to drinking water [1].

\footnotetext{
* Correspondence: adamdrew@uw.edu

${ }^{3}$ Center for Public Health Nutrition, University of Washington, 305 Raitt Hall, 4000 15th Ave NE, Box 353410, Seattle, WA 98195, USA

Full list of author information is available at the end of the article
}

The European Food Safety Authority (EFSA), has issued Dietary Reference Values (DRV) for water that were based, in part, on observed population intake of plain drinking water (tap and bottled); water from caloric and non-caloric beverages, and from food moisture. The EFSA adequate intake were set at $1600 \mathrm{ml} / \mathrm{d}$ for boys and girls aged 4-8 years; at $1900 \mathrm{ml} / \mathrm{d}$ for girls and at $2100 \mathrm{ml} / \mathrm{d}$ for boys aged 9-13 years [1]. The EFSA DRVs have been used as goals for individual intake [1]. Based on water-to-energy ratios, the desirable total water intake in children should be in the 1.0 to $1.5 \mathrm{~L} / 1000 \mathrm{kcal}$ range [1].

There is a growing literature on the consumption of plain drinking water by children and youth in the US [5-7], Mexico [8, 9], Germany [10, 11], Belgium [11, 12], 
and France $[11,13]$ and more recently in other countries such as Brazil, Argentina, Uruguay, Spain, Poland, UK, Turkey, Iran, China and Indonesia [8]. That literature attests to the importance of replacing caloric beverages in the diets of children with plain drinking water $[5,14,15]$. Given the high consumption of added sugars in the UK, the study of water consumption patterns (from plain water, beverages and foods) among UK children assumes a particular relevance.

The present goal was to examine the consumption of plain drinking water by children and youth in the UK, as distinct from the consumption of caloric beverages [15-17]. In this study, the nationally representative NDNS database (National Diet and Nutrition Survey 2008-2011) was used to assess total water consumption among British children aged 4-13 years. The NDNS is the principal national dietary survey for the UK that is jointly funded by Public Health England (PHE), an executive agency of the Department of Health, and by the UK Food Standards Agency (FSA). The NDNS is carried out by a consortium of three organizations: NatCen Social Research (NatCen), MRC Human Nutrition Research (HNR) and the University College London Medical School (UCL) [18].

Analyses reported below examined water consumption patterns by gender and age, socio-demographics characteristics, and by time and place of consumption. Additional analyses estimated total water sources (plain water, beverages, and foods) and the water-to-calorie ratios $(\mathrm{L} / \mathrm{kcal})$ in relation to the EFSA desirable norms. The NDNS is highly relevant to policy making; the data are used by the UK Government to develop policy and monitor progress on diet and nutrition objectives. This study was intended to inform one of those objectives related to the provision of safe, clean drinking water in schools [19].

\section{Methods \\ Dietary intake database: The National Diet and Nutrition survey (NDNS)}

The NDNS uses 4-day food records to provide estimates of diet, nutrient intake, and nutritional status for a representative sample of the UK population aged 1.5 years and older. The present pooled database was for three cycles of cross-sectional data collection $(2008 / 09,2009 / 10,2010 / 11)$. For each year, participants were asked to record food and drinks consumed both at home and away from home in diaries during 4 days, including weekend days. Data collection methods remain constant from year to year allowing data to be combined across survey years. Children aged 12 years and over were encouraged to complete the diaries themselves, while for children below 12 years the parent or caregiver was asked to complete the diary. The survey also included an interview to provide information on socio-demographic status and lifestyle [18].

Heights and weights were measured, using a portable stadiometer and weighing scales, the details of which are provided elsewhere [18]. Parents/guardians provided the written consent for taking measurements. Body Mass Index (BMI) values $\left(\mathrm{kg} / \mathrm{m}^{2}\right)$ were calculated and compared to pediatric standards [20]. The NDNS data were collected for a total sample of 3073 individuals, including 845 children aged 4-13 years. Ethical approval for NDNS was obtained from the Oxfordshire Research Ethics Committee. The consent form is available online [21].

\section{Age, gender, and sociodemographic status}

The two age groups were 4-8 years and 9-13 years old, corresponding to previous studies [5]. Regions of residence were defined as North, Central/Midlands, South (incl. London), and Scotland, Wales, and Northern Ireland. Ethnic groups were separated into white and non-white.

Household incomes were self-reported. Reported household incomes were first divided by an adjusted number of persons in the household to arrive at income-per-person. The income per consumption unit (IUC) was estimated by divided the total household income by the number of consumption unit of the household. The scale used to define a consumption unit was defined by the Organisation for Economic Co-operation and Development (OECD) [22] and is the most widely used at present [23]. It is measured as follows: one unit for the first adult, 0.5 for the others individuals of more than 14 years old and 0.3 for individuals of less than 14 years old. Then, the IUC was divided by quartiles.

\section{Plain water and beverage consumption}

Water and beverages were classified into these categories: tap water, bottled water, milks (including flavored), sodas (regular and diet), 100\% fruit juices, hot beverages (coffee and tea), fruit drinks, sports and energy drinks, flavored waters, and liquid supplements for nutrition use. All other foods were categorized as solid food.

Following past procedures [5], a distinction was made between the consumption of drinking water and beverages (in $\mathrm{g} / \mathrm{d}$ ) and the consumption of water from water, beverages, and foods (in $\mathrm{ml} / \mathrm{d}$ ). The NDNS food records for each respondent provided information on the amount in grams of each food and beverage consumed. The water content of beverages and the moisture content of foods were then established using a nutrient composition database [24].

Analyses of water and beverage consumption by eating occasion and eating location were based on the mean total weight of plain water and water from beverages calculated in $\mathrm{g} / \mathrm{d}$. By contrast, the comparisons to EFSA 
total water guidelines were for $\mathrm{ml}$ of water content from plain water, beverages, and foods, calculated in $\mathrm{ml} / \mathrm{d}$.

Data on the time of consumption were also provided in the NDNS. The time of consumption was assigned to one of 7 categories: 6 am-9 am, 9 am- 12 pm, 12 pm- 2 pm, 2 pm-5 pm, 5 pm- -8 pm, 8 pm-10 pm and 10 pm- 6 am. Time analyses were based on the entire sample; those children who consumed nothing during a given time period were assigned $0 \mathrm{~g}$ consumption.

Information on the place of food or beverage consumption was also examined. The key places reported were "at home", "at school", "friends", "fast-food", "coffee and restaurant", "other", and "unspecified". Analyses by place were conducted only for those children who declared that location as place of consumption. There could be multiple locations per child.

\section{Statistical analyses}

Analyses evaluated the survey-weighted mean 4-day water intake overall and by age-group, gender, and IUC. The consumption of plain water, tap and bottled, was evaluated separately for the entire population and by age-group, gender and IUC. The consumption of water and beverages (milk, sodas, juice, hot drinks, fruit drinks, sport and energy drinks, flavored water and supplements), and total water intake from beverages and foods were estimated by socio-demographic status, seasonality, BMI, ethnicity, region, the time and the place of consumption. Total water intake from water, beverages, and solid foods were estimated in $\mathrm{ml} / \mathrm{d}$ for the total population and subgroups of interest.

All analyses by gender, age, IUC, season, BMI, ethnic group and region were based on ANOVAs. Post-hoc comparisons between means using Bonferroni correction were performed where indicated. Tests of percentages of children failing to meet EFSA recommendations were based on non-parametric Chi square test. The estimated percent of children meeting the Dietary Reference Intake (DRI) for water represents the upper bound of the estimate, since the mean of 4 days' water intake may not represent the habitual intake of an individual. Total water intake per $1000 \mathrm{kcal}$ and total energy intake from food groups were compared by gender and age. An additional multiple regression was conducted to examine the effect of IUC on water consumption, adjusting for covariates. The tests were conducted using the SAS statistical software package version 9.4 and the SURVEYREG, SURVEYMEANS and SURVEYFREQ procedures.

Total water intake were expressed as percent EFSA guideline $(1600 \mathrm{ml} / \mathrm{d}$ for boys and girls $4-8$ years; $2100 \mathrm{ml} / \mathrm{d}$ for boys 9-13 years and $1900 \mathrm{ml} / \mathrm{d}$ for girls $9-13$ years). The percent of children not meeting
EFSA guidelines was calculated. Associations between age, gender and compliance with EFSA standards were tested with a non-parametric Chi square test. Statistical significance level was 0.01 to take multiple statistical tests into account [25].

\section{Results}

\section{Plain water consumption}

The consumption of plain water $(\mathrm{ml})$ by age, gender, and socio-demographic group is shown in Table 1 . On average, children aged 4-13 years drank a total of $258 \mathrm{ml} / \mathrm{d}$ of water. Most of the water (83.8\%) came from the tap. Overall, children consumed $216 \mathrm{ml}$ tap water and only $42 \mathrm{ml}$ bottled water. Older children drank more bottled water than did younger children $(54 \mathrm{ml}$ vs $29 \mathrm{ml})$. There was no significant difference between boys $(234 \mathrm{ml})$ and girls $(283 \mathrm{ml})$ in terms of water intake.

Table 1 also shows that the consumption of tap water (but not bottled water) rose sharply with income. Whereas children in the lowest IUC quartile consumed $146 \mathrm{ml} / \mathrm{d}$, those in the highest quartile consumed $267 \mathrm{ml} / \mathrm{d}$. Most tap water was consumed in the South of England, including London $(264 \mathrm{ml} / \mathrm{d})$, significantly more than in the North $(178 \mathrm{ml} / \mathrm{d})$ or in Scotland, Wales and Northern Ireland $(166 \mathrm{ml} / \mathrm{d})$. The effect of income quartiles on the consumption of total water (bottled and tap) and for tap water remained significant in multiple regression models, adjusted for age, gender, BMI classes, ethnicity and region (data not shown). In every case, the quartile Q1 was significantly different from quartiles Q3 and Q4.

There were no significant differences by gender, BMI status, or seasonality for tap or bottled water consumption. Non-white participants consumed more tap water (271 vs $205 \mathrm{ml}$ ) but not significantly $(p=0.012)$.

\section{Consumption of plain water and other beverages}

Table 2 shows that the combined consumption of plain water and beverages was $953.2 \mathrm{~g}$. Older children drank more than did younger children (1008 g vs $897 \mathrm{~g}$ ). There was no difference in total beverages consumption between boys and girls. There was a significant effect of income and a weaker effect of overweight.

Different age, gender, ethnicity, and socioeconomic effects were obtained for different caloric and noncaloric beverages. The consumption of milk declined with age. Boys drank more milk than did girls. The consumption of soda, sports and energy drinks, and tea and coffee increased sharply with age, but was not affected by gender.

Only the consumption of $100 \%$ juice increased with income. No effect of IUC was observed for any other beverage shown. While lower income groups consumed more tea and coffee, the effect was not 
Table 1 The consumption of tap and bottled water $(\mathrm{ml} / \mathrm{d})$ by children in the NDNS sample $(n=845)$ by age group, gender, and socio-demographic group. The data are means and standard deviations (Std)

\begin{tabular}{|c|c|c|c|c|c|c|c|}
\hline \multirow{3}{*}{$\overline{\text { All }}$} & \multicolumn{3}{|c|}{ Water (Tap + Bottled) } & \multicolumn{2}{|c|}{ Tap water } & \multicolumn{2}{|c|}{ Bottled water } \\
\hline & N & Mean & $\overline{S t d^{1}}$ & Mean & $\overline{S t d^{1}}$ & Mean & $\overline{S t d^{1}}$ \\
\hline & 845 & 257.6 & 275.7 & 215.9 & 259.8 & 41.7 & 116.2 \\
\hline \multicolumn{8}{|l|}{ Age (years) } \\
\hline $4-8$ & 436 & 241.0 & 245.4 & 212.4 & 228.0 & 28.6 & 94.9 \\
\hline \multirow[t]{2}{*}{$9-13$} & 409 & 273.7 & 304.0 & 219.3 & 290.1 & 54.4 & 134.0 \\
\hline & & \multicolumn{2}{|c|}{0.1061} & \multicolumn{2}{|c|}{0.7018} & \multicolumn{2}{|c|}{0.0041} \\
\hline \multicolumn{8}{|l|}{ Gender } \\
\hline Boys & 430 & 233.7 & 247.6 & 192.8 & 229.5 & 40.9 & 118.0 \\
\hline \multirow[t]{2}{*}{ Girls } & 415 & 282.7 & 300.3 & 240.1 & 286.0 & 42.5 & 114.4 \\
\hline & & \multicolumn{2}{|c|}{0.0284} & \multicolumn{2}{|c|}{0.0275} & \multicolumn{2}{|c|}{0.8543} \\
\hline \multicolumn{8}{|l|}{ Quartiles of IUC } \\
\hline Q1 (poorer) & 148 & 177.1 & 193 & 145.8 & 175.9 & 31.3 & 97.0 \\
\hline Q2 & 186 & 260.7 & 282.6 & 208.7 & 249.9 & 52.0 & 135.6 \\
\hline Q3 & 215 & 272.6 & 256.4 & 240.0 & 251.5 & 32.6 & 96.6 \\
\hline \multirow[t]{2}{*}{ Q4 (richer) } & 197 & 318.9 & 331.8 & 266.5 & 319.4 & 52.4 & 125.6 \\
\hline & & \multicolumn{2}{|c|}{$<0.0001^{\mathrm{a}}$} & \multicolumn{2}{|c|}{$<0.0001^{\mathrm{a}}$} & \multicolumn{2}{|c|}{0.2319} \\
\hline \multicolumn{8}{|l|}{ Season } \\
\hline Winter & 230 & 241.8 & 224.8 & 208.8 & 212.7 & 33.0 & 92.6 \\
\hline Spring & 233 & 286.7 & 308.2 & 234.0 & 280.0 & 52.8 & 138.8 \\
\hline Summer & 207 & 242.0 & 238.2 & 194.7 & 225.1 & 47.3 & 119.1 \\
\hline \multirow[t]{2}{*}{ Fall } & 175 & 254.3 & 326.3 & 223.9 & 319.5 & 30.4 & 105.9 \\
\hline & & \multicolumn{2}{|c|}{0.3518} & \multicolumn{2}{|c|}{0.4019} & \multicolumn{2}{|c|}{0.119} \\
\hline \multicolumn{8}{|l|}{ BMI } \\
\hline Under/normal & 607 & 261.0 & 282.4 & 221.2 & 268.9 & 39.8 & 112.3 \\
\hline \multirow[t]{2}{*}{ Overweight/obese } & 204 & 251.8 & 250.9 & 208.6 & 236.1 & 43.2 & 116.5 \\
\hline & & \multicolumn{2}{|c|}{0.6973} & & & & \\
\hline Ethnic group & & & & & & & \\
\hline White & 723 & 247.1 & 270.4 & 205.0 & 254.7 & 42.1 & 118.1 \\
\hline Non white & 122 & 310.7 & 299.7 & 271.1 & 281.6 & 39.6 & 104.5 \\
\hline & & & & & & & \\
\hline Region & & & & & & & \\
\hline England: North & 201 & 234.4 & 233.5 & 178.2 & 208.4 & 56.2 & 137.4 \\
\hline England: Central/Midlands & 142 & 207.3 & 240.1 & 184.4 & 229.0 & 22.9 & 88.8 \\
\hline England: South (incl. London) & 355 & 303.6 & 317.4 & 264.2 & 305.0 & 39.4 & 112.0 \\
\hline Scotland,Wales, Northern Ireland & 147 & 210.9 & 232.2 & 165.8 & 206.9 & 45.1 & 115.9 \\
\hline & & & & & & & \\
\hline
\end{tabular}

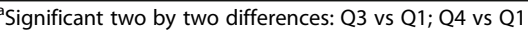

bSignificant two by two differences: England South vs Scotland, Wales, Northern Ireland

'Significant two by two differences: England Central vs England South

${ }^{\mathrm{d}}$ Significant two by two differences: England North vs England South

${ }^{1}$ Std: Standard Deviation

2IUC: Income per Consumption Unit

Comparisons between two means were either significant (bold) or not

statistically significant. Whites consumed much more flavored water and fruit drinks than did non-whites. Milk consumption was higher in Scotland, Wales and Northern Ireland than in the South of England. Overweight and obese children drank more water and beverages than normal-weight children; however trends for fruit drinks and soda were not significant at 0.01 level.
Water and beverage consumption by time of day and location

Figure 1 shows that most water and beverages was consumed between $5 \mathrm{pm}$ and $8 \mathrm{pm}(207 \mathrm{~g} / \mathrm{d})$, corresponding to dinner time, followed by times corresponding to lunch (176 g/d), and breakfast (167 g/d). Beverage choices shifted by time of day. Plain water consumption was higher between $12 \mathrm{pm}$ to $2 \mathrm{pm}$ (lunch) and between 


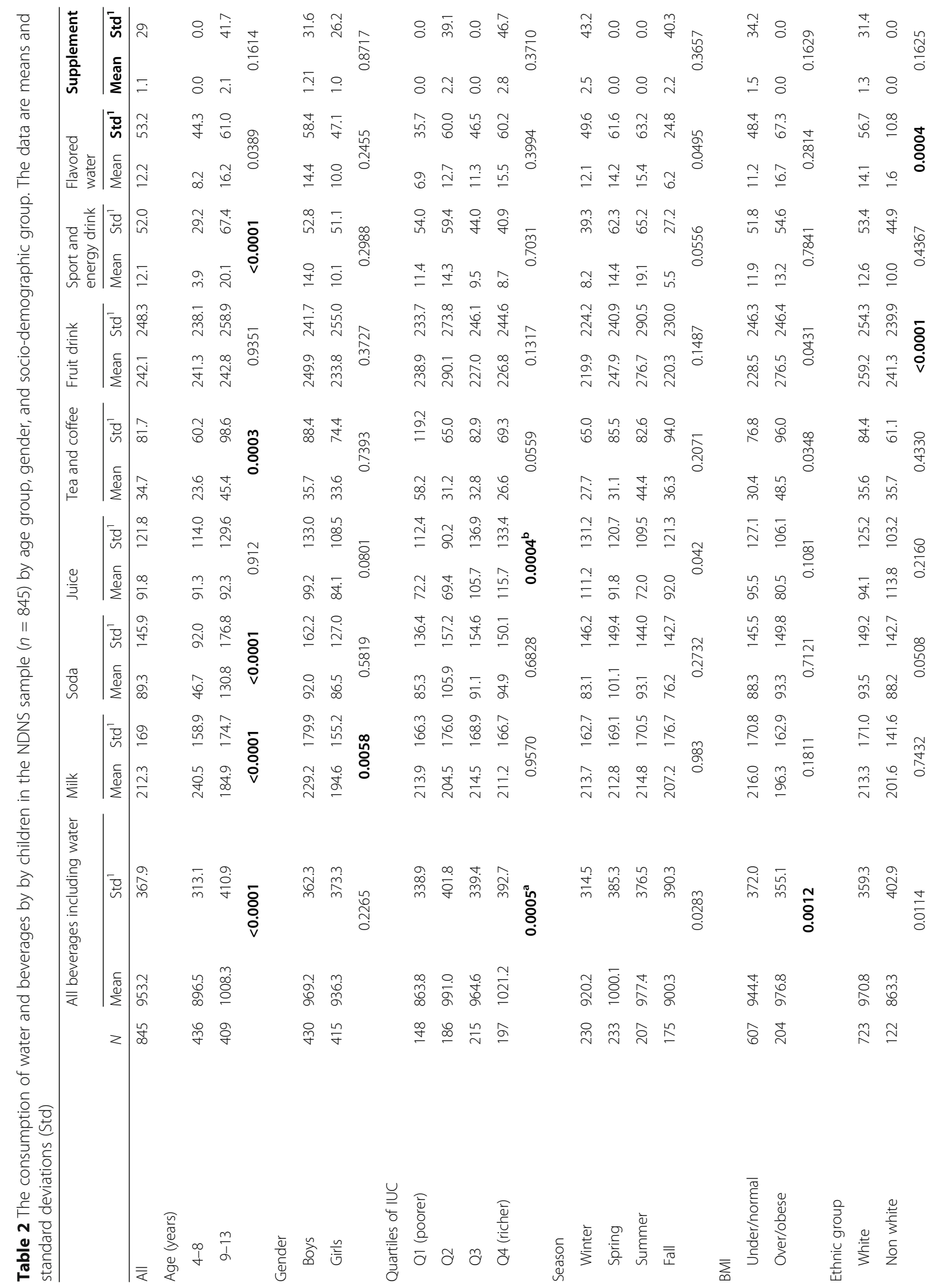




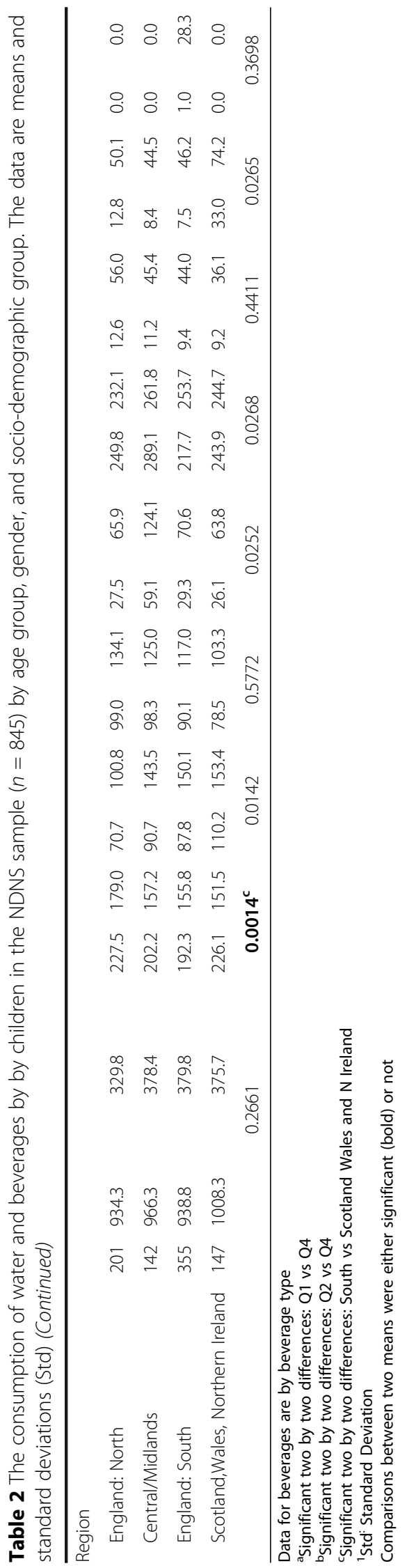


$5 \mathrm{pm}$ to $8 \mathrm{pm}$ (dinner) than at any other time. Breakfast was the occasion to consume milk (84 g) and 100\% juice, followed by fruit drinks and water. Tea and coffee were mostly consumed from 6 to 9 am (12 g). Water $(62 \mathrm{~g})$, fruit drinks (57 g) and juices (21 g) were consumed at lunch. Fruit drinks (66 g), water (57 g), soda (30 g) and milk (28 g) were consumed around dinner time (5-8 pm). Milk came back between 8 and $10 \mathrm{pm}$ (33 g). Most sugar sweetened soda was consumed at dinner time $(30 \mathrm{~g})$ and during the afternoon hours $(23 \mathrm{~g})$. Beverage consumption at night (10 pm to $6 \mathrm{am})$ was very low.

Breakfast was thus characterized by the consumption of milk, $100 \%$ juices, and tea and coffee. Lunch was the occasion to consume fruit drinks, water and $100 \%$ juice. Morning snacks favored milk over fruit drinks, whereas afternoon snacks (between 2 pm to 5 pm) had less milk but more fruit drinks and soda.

Figure 2 shows water and beverage consumption by location. Each NDNS respondent could list multiple locations for beverage consumption; per consumer analyses were based on declared respondents for that location only. The most common reported location was home $(n=845)$, followed by school $(n=640)$, friends $(n=360)$, Fast food restaurant (FFR, $n=110)$, café restaurant $(n=219)$ and other $(n=583)$.

For example, all 845 children consumed a beverage at home over the 4 days of NDNS. Average consumption was $47 \mathrm{~g}$ of water, most of it from the tap (43 g). More water was consumed at school $(75 \mathrm{~g})$, most of it also from the tap $(60 \mathrm{~g})$. Less tap water was consumed in a fast-food (14 g) or in a café (21 g). By contrast, less bottled water was consumed at home $(5 \mathrm{~g})$ than at school (15 g) or other places (20 g).
Whereas total beverages consumption was highest in café-restaurants $(261 \mathrm{~g})$ and in fast-foods $(244 \mathrm{~g})$, milk was mainly consumed at home (55 g). By contrast, sodas were consumed away from home, mostly in café-restaurants (110 g) and in fast-foods (106 g). About $40 \%$ of beverages consumed in restaurants were sodas. Tea and coffee were more likely to be consumed at home and at friends' homes, whereas $100 \%$ juices were more likely to be consumed in restaurants (see Fig. 2). Whereas the consumption of fruit drinks was ubiquitous, more flavored water was consumed away from home. The consumption of sport and energy drinks was very low.

\section{Total water intake from drinking water, beverages, and food moisture}

Table 3 shows the main sources of total daily water intake (ml) by age, gender, ethnicity, season, BMI and sociodemographic group. Mean total water intake from plain water, beverages and foods was $1338 \mathrm{ml}$. Water and beverages together contributed $901 \mathrm{ml}$ (67\%), with beverages accounting for $48 \%$ of it, whereas food moisture contributed $437 \mathrm{ml}$ (33\%).

Older children had higher total water intake $(1396 \mathrm{ml})$ than did younger children $(1278 \mathrm{ml})$. There was no difference between boys and girls. There was a sharp effect of incomes: highest income groups had higher total water intake than did lowest income groups. White children consumed more total water than did non-white children. There were no differences in total water intake by BMI, seasonality, or region.

The effect of age, but not gender, was observed for combined water and beverages. Higher consumption

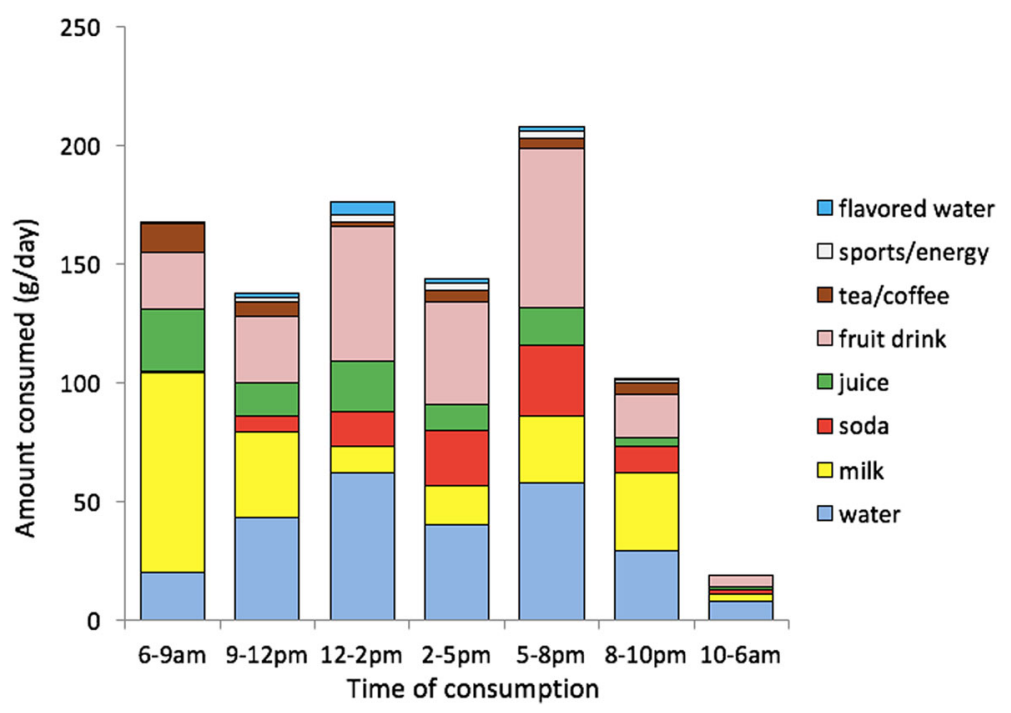

Fig. 1 Time distribution of water and beverage consumption by beverage category for children aged 4-13 years 


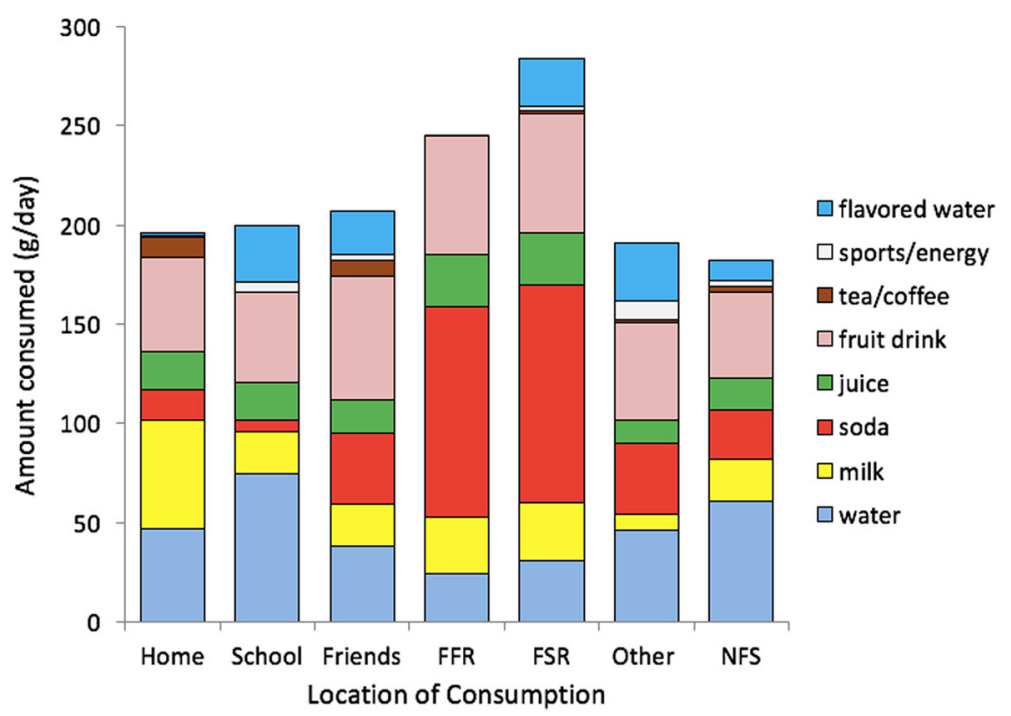

Fig. 2 Water and beverage consumption by location. The most common reported location was home $(n=845)$, followed by school $(n=640)$, friends $(n=360)$, FFR $(n=110)$, café restaurant $(n=219)$ and other $(n=583)$. Abbreviations: FFR- fast food restaurant; FSR- full service restaurant; NFS- not further specified

was observed for Whites and the highest income group as compared to the lowest.

Figure 3 shows total water consumption according to the age by gender categories. As previously reported, milk consumption for 9-13 year old girls was significantly lower than for 4-8 year old children (boys or girls). Conversely, older boys and girls (9-13 years age group) drank significantly more soda than did younger boys and girls ( $4-8$ years age group).

\section{Meeting EFSA recommendations}

Total water intake in relation to the EFSA standards are shown in Fig. 4. The shortfall in water consumption is indicated as well. For, 4-8 years old boys and girls, the shortfall was $322 \mathrm{ml}$, whereas for 9-13 years olds it was $548 \mathrm{ml}$ for girls and $659 \mathrm{ml}$ for boys. The percent of children who failed to meet EFSA guidelines was $88.7 \%$ (84.4\% for $4-8$ years group and $92.8 \%$ for $9-13$ years group). Mean total water intake among children aged 413 years covered only $74.8 \%$ of EFSA recommended amounts $(79.9 \%$ for younger children and $69.9 \%$ for older children).

Additional analyses calculated total water intake per $1000 \mathrm{kcal}$ by gender and age. Overall, the ratio was $0.845 \mathrm{~L} / 1000 \mathrm{kcal}$ ( 0.83 for boys and 0.86 for girls). No significant differences by gender were observed after adjusting for energy.

\section{Discussion}

The present study adds to the existing literature on water consumption in the UK [8] and allows for a direct comparison of children's water drinking habits in France and the US [5, 27]. Those prior analyses were also conducted using nationally representative databases collected by the respective governments. Dietary intake methodologies were comparable. Whereas the French INCA data were based on 7-day food records, the British NDNS used 4-day food records. Our past studies, conducted in the US and in France [5, 26], used the same age groupings (4-13 years), the same beverage classification scheme, and also distinguished between tap and bottled water. Total water intakes were compared to adequate water intake by age group, as defined by EFSA and by the US Institute of Medicine [5, 26].

Plain water consumption in UK was estimated at $258 \mathrm{~g} / \mathrm{d}$. The bulk of water came from the tap (84\%); only $16 \%$ came from bottled water. By contrast, plain water consumption in France was estimated at $453 \mathrm{ml} / \mathrm{d}$, of this $242 \mathrm{ml}$ came from the tap (54\%) and $210 \mathrm{ml}$ (46\%) from bottled water [26]. In the US, plain water consumption among 4-13 year olds was $431 \mathrm{ml} / \mathrm{d}$, of this $257 \mathrm{ml}$ (59.6\%) came from tap and $174 \mathrm{ml}(40.4 \%)$ from bottled water.

Plain water consumption among UK children varied by household income. The effect of income was observed for total and for tap but not for bottled water, in part because of low levels of consumption of bottled water. A similar income gradient for tap water consumption was observed in the US; it was significant for adults but only marginal for children $[4,5]$. By contrast, water consumption (tap and bottled) among French children was much higher overall and no income gradient was observed [26]. 
Table 3 The consumption of water from water and beverages and from food moisture by children in the NDNS sample $(n=845)$ by age group, gender, and socio-demographic group. The data are means and standard deviations (Std)

\begin{tabular}{|c|c|c|c|c|c|c|c|}
\hline & \multicolumn{3}{|c|}{ Water Total } & \multicolumn{2}{|c|}{ Water + Beverage } & \multicolumn{2}{|c|}{ Food moisture } \\
\hline & $\bar{N}$ & Mean & $S t d^{1}$ & Mean & $\mathrm{Std}^{1}$ & Mean & $\mathrm{Std}^{1}$ \\
\hline All & 845 & 1338.2 & 400.6 & 901.2 & 355.8 & 437.0 & 133.0 \\
\hline \multicolumn{8}{|l|}{ Age (years) } \\
\hline $4-8$ & 436 & 1278.5 & 350.8 & 845.9 & 304.2 & 432.6 & 126.5 \\
\hline \multirow[t]{2}{*}{$9-13$} & 409 & 1396.3 & 439.7 & 955.0 & 396.1 & 441.3 & 139.5 \\
\hline & & \multicolumn{2}{|c|}{$<0.0001$} & \multicolumn{2}{|c|}{$<0.0001$} & \multicolumn{2}{|c|}{0.4122} \\
\hline \multicolumn{8}{|l|}{ Gender } \\
\hline Boys & 430 & 1359.4 & 390.2 & 913.6 & 347.4 & 445.7 & 135.2 \\
\hline \multirow[t]{2}{*}{ Girls } & 415 & 1316.0 & 410.3 & 888.1 & 364.3 & 427.9 & 130.1 \\
\hline & & \multicolumn{2}{|c|}{0.1548} & \multicolumn{2}{|c|}{0.3352} & \multicolumn{2}{|c|}{0.0618} \\
\hline \multicolumn{8}{|l|}{ Quartiles of IUC } \\
\hline Q1 (poorer) & 148 & 1216.0 & 366.0 & 812.0 & 321.0 & 404.0 & 137.5 \\
\hline Q2 & 186 & 1372.5 & 431.3 & 940.7 & 390.5 & 431.7 & 133.4 \\
\hline Q3 & 215 & 1358.5 & 380.6 & 913.5 & 327.8 & 445.0 & 133.5 \\
\hline \multirow[t]{2}{*}{ Q4 (richer) } & 197 & 1431.7 & 417.4 & 966.5 & 382.3 & 465.2 & 122.9 \\
\hline & & \multicolumn{2}{|c|}{$<0.0001^{\text {abc }}$} & \multicolumn{2}{|c|}{$0.0002^{\mathrm{ac}}$} & \multicolumn{2}{|c|}{$0.0015^{c}$} \\
\hline \multicolumn{8}{|l|}{ Season } \\
\hline Winter & 230 & 1305.8 & 359.8 & 868.8 & 303.2 & 436.9 & 122.7 \\
\hline Spring & 233 & 1376.8 & 409.9 & 944.2 & 371.7 & 432.5 & 131.3 \\
\hline Summer & 207 & 1368.0 & 407.6 & 926.3 & 364.7 & 441.6 & 138.5 \\
\hline \multirow[t]{2}{*}{ Fall } & 175 & 1289.7 & 424.5 & 851.8 & 379.5 & 438.0 & 142.2 \\
\hline & & \multicolumn{2}{|c|}{0.0836} & \multicolumn{2}{|c|}{0.0337} & \multicolumn{2}{|c|}{0.9305} \\
\hline \multicolumn{8}{|l|}{ BMI } \\
\hline Under/normal & 607 & 1330.6 & 409.5 & 891.3 & 359.5 & 439.3 & 135.1 \\
\hline \multirow[t]{2}{*}{ Over/obese } & 204 & 1356.7 & 368.9 & 929.4 & 343.8 & 427.3 & 127.8 \\
\hline & & \multicolumn{2}{|c|}{0.4514} & & & & \\
\hline Ethnic group & & & & & & & \\
\hline White & 723 & 1358.1 & 391.5 & 918.6 & 347.8 & 439.4 & 132.9 \\
\hline Non white & 122 & 1237.2 & 436.4 & 812.6 & 387.7 & 424.6 & 133.2 \\
\hline & & & & & & & \\
\hline Region & & & & & & & \\
\hline England: North & 201 & 1313.2 & 365.2 & 880.4 & 316.2 & 432.9 & 129.3 \\
\hline England: Central/Midlands & 142 & 1360.4 & 418.6 & 915.8 & 365.0 & 444.7 & 122.7 \\
\hline England: South (incl. London) & 355 & 1323.0 & 411.0 & 889.6 & 370.7 & 433.3 & 132.2 \\
\hline Scotland,Wales, Northern Ireland & 147 & 1395.8 & 401.2 & 949.8 & 360.2 & 446.0 & 149.0 \\
\hline & & & & & & & \\
\hline
\end{tabular}

${ }^{a}$ Significant two by two differences: Q2 vs Q1

bSignificant two by two differences: Q3 vs Q1

'Significant two by two differences: Q4 vs Q1

${ }^{1}$ Std: Standard Deviation

Comparisons between two means were either significant (bold) or not

Beverage consumption patterns in the UK also depended on incomes. Higher income groups in the UK consumed more water and more beverages than did lower-income groups; the effect was driven by tap water and by $100 \%$ fruit juice. Lower income children tended to consume more tea.

Total water consumption from plain water and beverages was $901 \mathrm{~g}$ in the UK, $801 \mathrm{~g}$ in France, and $1136 \mathrm{~g}$ in 


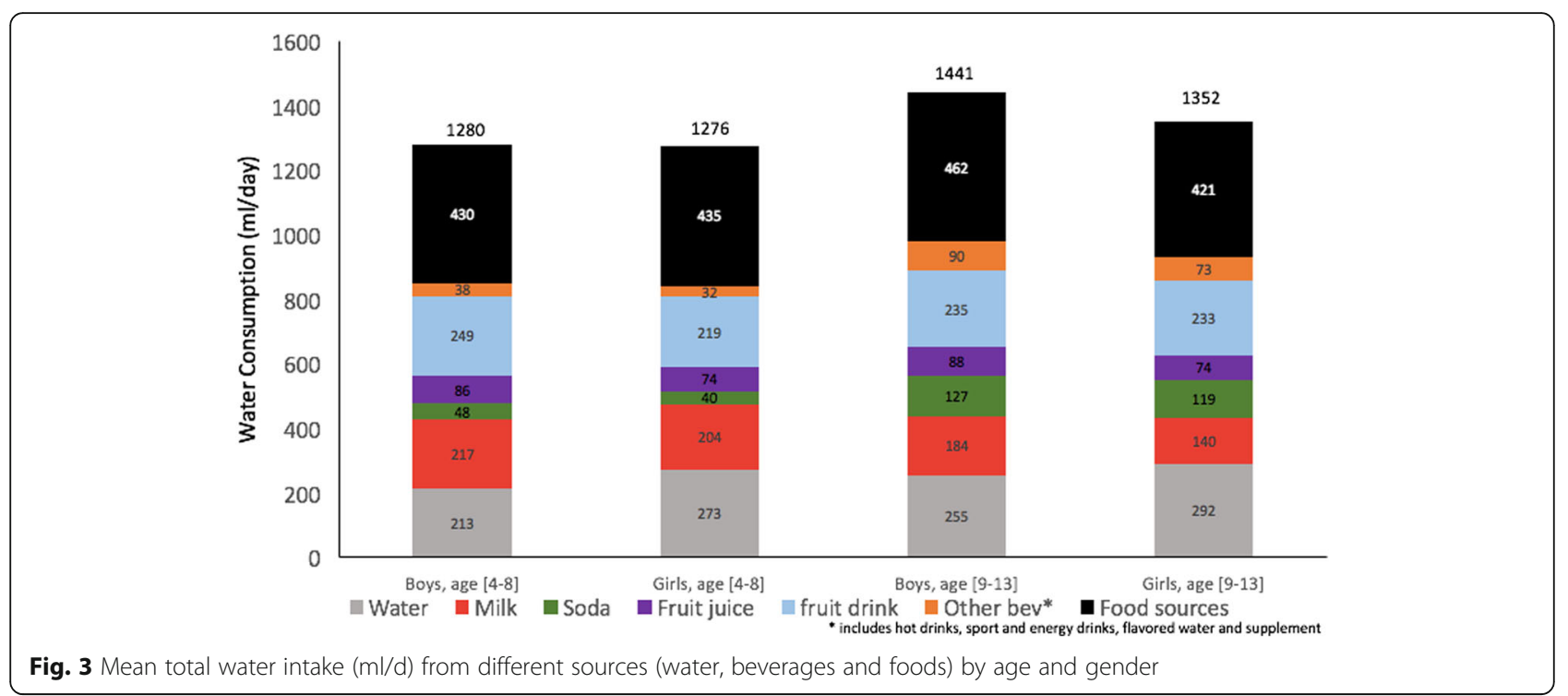

the US $[5,26]$. Patterns of beverage consumption varied by age. Milk consumption declined with age whereas the consumption of sweetened beverages increased, consistent with other data from France [26, 27], the UK [16], and the US [5]. Total water intakes in the UK, but not in France, varied with income.

The consumption of sweetened fruit drinks by UK children $(242 \mathrm{ml} / \mathrm{d}$ water) was significantly above US values for regular fruit drinks $(79 \mathrm{ml} / \mathrm{d}$ water) and was more than double the consumption of soda $(89 \mathrm{ml} / \mathrm{d}$ water). By contrast, French children derived water from drinking water, then milk, then $100 \%$ juice and only then soda [26]. The consumption of sweetened fruit-based drinks in France was negligible [26], in marked contrast to the UK. In the US the children drank more soda than either fruit juices or fruit drinks [5].

There were only minor differences by race/ethnicity in the UK . By contrast, the patterns of tap versus bottled water consumption in the US varied by age, gender and race/ethnicity [5, 7]. Non-Hispanic white children drank more water than did Mexican American and nonHispanic black children.

Analyses by time and place of consumption allowed for further insights into UK children's water drinking habits. In the UK, water and sweetened beverages were mostly consumed at lunch and dinner times; the

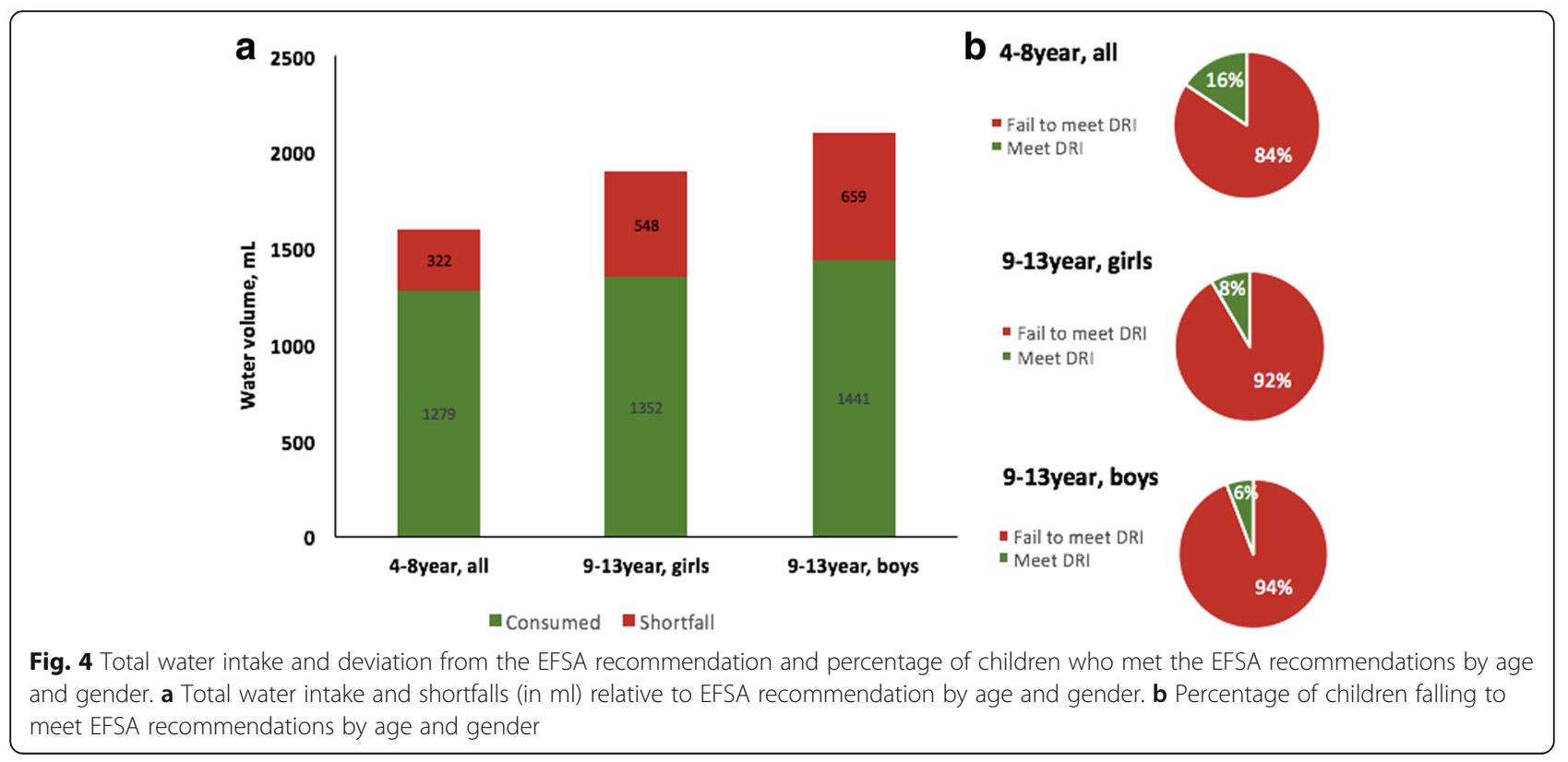


dominant beverage at breakfast was milk. Fruit drinks equaled or exceeded plain water consumption between 12 noon and $10 \mathrm{pm}$. By contrast, French children drank virtually no fruit drinks at all [26]. Breakfast was characterized by milk and $100 \%$ fruit juice almost exclusively [26]. The dominant beverage at lunch and dinner in France was plain water, bottled and tap, whereas soda consumption was low [26]. Clearly, there are major cultural differences between the UK and France with respect to what beverages are viewed as appropriate for children's meals and snacks. A similar analysis by time and place of consumption for the US would be of great interest.

British children drank most milk at home and most plain water at school. By contrast, beverages consumed at full service and quick service restaurants tended to be soda and fruit drinks and to a much smaller extent plain water and milk. The present data would suggest that British children appeared to consume more beverages away from home than did French children. Bellisle et al. [13] had previously noted that French children consumed about $80 \%$ of the total daily fluid intake at home [13]. However, data on the place of consumption ought to be interpreted cautiously, given many instances of places identified as other or unspecified.

Total water consumption from water, beverages, and food moisture in the UK was estimated at $1338 \mathrm{ml} / \mathrm{d}$. Of this $901 \mathrm{ml}$ was provided by water and beverages and $437 \mathrm{ml} / \mathrm{d}$ by moisture from foods. Total water consumption in France for the same age group was estimated at $1324 \mathrm{ml} / \mathrm{d}$ - a wholly remarkable level of agreement. Of this, $801 \mathrm{ml}$ was provided by beverages and $524 \mathrm{ml}$ by moisture from food. Total water consumption in the US was estimated at $1580 \mathrm{ml}$. Of this, $1136 \mathrm{ml}$ was provided by water and beverages and $447 \mathrm{ml}$ by food moisture.

French children derived more water from food moisture $(39 \%)$ than did children in the UK $(33 \%)$ or in the US (28\%). That may say something about the quality of the diet, given that, in general, higher levels of moisture from food point to a lower energy density diet with more vegetables and fruit.

Comparisons of water intake from all sources to EFSA guidelines were consistent with past findings. Water intake in UK covered only $74.8 \%$ of EFSA recommendations and $88.7 \%$ of all children failed to meet the guidelines. Very similar figures had been obtained for France: guidelines were not met by $89 \%$ of all $4-8$ year olds and $90 \%$ or more for $9-13$ year olds. In Belgium noncompliance was $93 \%$ for girls and $92 \%$ for boys in the 9-13 years age range [12]. By contrast, fewer US children failed to meet the (higher) recommendations issued by the US Institute of Medicine. Indeed, $85 \%$ of the recommendations were covered for 4-8 years old children, 78\% for 9-13 years old girls and 73\% for 9-13 years old boys. Failing to meet the guidelines were $75 \%$ of
4-8 year olds and about $84 \%$ of $9-13$ year olds [5]. Of course, it needs to be stressed that not meeting guidelines does not imply dehydration or any adverse medical condition; merely that the existing guidelines for adequate water intake are not being met.

Replacing caloric beverages with plain drinking water is a public health priority in the UK, the US and in France $[1,2]$. UK based studies [17], using a longitudinal cohort, have already examined the impact of sugar-sweetened beverage (SSB) consumed by $5-7$ year olds on BMI values at 9 years of age.

The cultural differences in water drinking habits between the UK and France may suggest new avenues for intervention. First, French children consumed much more plain water, tap and bottled [26], than did UK children whose consumption patterns ran toward sweetened beverages, mostly fruit drinks. Second, plain water was the almost exclusive beverage of choice at lunch and dinner in France [26]; not the case in the UK. Third, water, both bottled and tap, was the almost exclusive beverage in French schools, again, not the case in the UK. As noted before, the consumption of plain tap water in the UK was higher among higher income households; no comparable social gradient was observed in France [26]. By contrast, consumption habits by time and place were comparable. Beverages were consumed mostly with meals. Whereas milk was consumed at home, sweetened beverages (sodas, fruit drinks) were consumed outside, principally for afternoon snacks and lunch.

The study had limitations. First, the NDNS data, based on self-report, are subject to random inaccuracies and to systematic reporting biases. The proxy recall for younger children may be an additional source of bias. The 4 days of food records impose a burden on respondents and data quality can be variable. The NDNS database is the standard source of information about dietary intake in the UK and is comparable in scope and importance to the National Health and Nutrition Examination Survey in the US and the INCA 2 database in France.

\section{Conclusions}

The present analyses represent one of the first explorations of the consumption of drinking water relative to sugary beverages by children in the UK and suggest potential avenues for intervention. Based on cumulative evidence from multiple countries $[8,15]$, it seems reasonable to promote the consumption of plain water as the beverage of choice to meet the daily hydration needs. Healthy food and beverage patterns, developed during childhood, are an integral component of a healthy lifestyle.

\section{Abbreviations}

BMI: Body Mass Index; DRI: Dietary Reference Intakes; DRV: Dietary Reference Values; EFSA: European Food Safety Authority; FFR: Fast Food Resturant; 
FSA: Food Standards Agency; FSR: Full service restaurant; HNR: Human Nutrition Research; INCA: Étude Individuelle Nationale des Consommations Alimentaires; IUC: Income per Consumption Unit; NatCen: National Centre for Social Research; NDNS: National Diet and Nutrition Survey; NFS: Not further specified; OECD: Organisation for Economic Co-operation and Development; PHE: Public Health England; Std: Standard Deviation; UCL: University College London

\section{Acknowledgements}

Not Applicable.

\section{Funding}

Analyses of the British national NDNS database were supported by Nestlé Waters MT, Paris, France. Nestlé had no role in the UK NDNS study design or in the conduct of secondary data analyses.

\section{Availability of data and materials}

The dataset supporting the conclusions of this article is available in the National Centre for Social Research repository (unique persistent identifier: 10.5255/UKDA-SN-6533-6; hyperlink to database http://dx.doi.org/10.5255/ UKDA-SN-6533-6.)

\section{Authors' contributions}

The present study was designed by FV, MM, and FC. Analyses were performed by FV and MM. AD took the lead on writing the manuscript. All authors reviewed and approved the final manuscript.

\section{Competing interest}

FV and MM are employed by MS-nutrition, a research start up. FC is employed by Nestlé Waters France. AD is a consultant to Nestlé and has received research grants, honoraria, consulting fees from numerous food, beverage, and ingredient companies and other commercial and nonprofit entities with interests in nutrient density of the diet.

\section{Consent for publication}

Not applicable.

\section{Ethics approval and consent to participate}

Ethical approval for NDNS was obtained from the Oxfordshire Research Ethics Committee.

\section{Publisher's Note}

Springer Nature remains neutral with regard to jurisdictional claims in published maps and institutional affiliations.

\section{Author details}

${ }^{1}$ MS-Nutrition, Faculté de Médecine La Timone, Marseille, France. ${ }^{2}$ Nestlé Waters M.T, 12 boulevard Garibaldi, 92130 Issy-les-Moulineaux, France. ${ }^{3}$ Center for Public Health Nutrition, University of Washington, 305 Raitt Hall, 4000 15th Ave NE, Box 353410, Seattle, WA 98195, USA

Received: 14 May 2016 Accepted: 9 May 2017

Published online: 19 May 2017

\section{References}

1. EFSA Panel on Dietetic Products, Nutrition and Allergies. Scientific opinion on dietary reference values for water. EFSA J. 2010;8(3):1459.

2. Institute of Medicine. Dietary reference intakes for water, potassium, sodium, chloride, and sulfate. Washington, DC: The National Academies Press; 2004

3. Kant AK, Graubard Bl, Atchison EA. Intakes of plain water, moisture in foods and beverages, and total water in the adult US population-nutritional, meal pattern, and body weight correlates: National Health and nutrition Examination surveys 1999-2006. Am J Clin Nutr. 2009;90(3):655-63.

4. Drewnowski A, Rehm CD, Constant F. Adults in the United States: crosssectional study using data from NHANES 2005-2010. BMC Public Health. 2013;13(1):1068

5. Drewnowski A, Rehm CD, Constant F. Water and beverage consumption among children age 4-13y in the United States: analyses of 2005-2010 NHANES data. Nutr J. 2013;12:85.
6. Park S, Blanck HM, Sherry B, Brener N, O'Toole T. Factors associated with low water intake among US high school students - National Youth Physical Activity and nutrition study, 2010. J Acad Nutr Diet. 2012;112(9):1421-7.

7. Kant AK, Graubard BI. Contributors of water intake in US children and adolescents: associations with dietary and meal characteristics-National Health and nutrition Examination survey 2005-2006. Am J Clin Nutr. 2010;92(4):887-96.

8. Iglesia I, Guelinckx I, De Miguel-Etayo PM, González-Gil EM, Salas-Salvadó J, Kavouras SA, et al. Total fluid intake of children and adolescents: cross-sectional surveys in 13 countries worldwide. Eur J Nutr. 2015;54(Suppl 2):57-67.

9. Piernas C, Barquera S, Popkin BM. Current patterns of water and beverage consumption among Mexican children and adolescents aged 1-18 years: analysis of the Mexican National Health and nutrition survey 2012. Public Health Nutr. 2014;17(10):2166-75.

10. Sichert-Hellert W, Kersting M, Manz F. Fifteen year trends in water intake in German children and adolescents: results of the DONALD study. Dortmund nutritional and anthropometric longitudinally designed study. Acta Paediatr. 2001;90(7):732-7.

11. Duffey K, Huybrechts I, Mouratidou T, Libuda L, Kersting M, De Vriendt T, et al. Beverage consumption among European adolescents in the HELENA study. Eur J Clin Nutr. 2012;66(2):244-52.

12. Senterre $C$, Dramaix $M$, Thiébaut I. Fluid intake survey among schoolchildren in Belgium. BMC Public Health. 2014;14(1):651.

13. Bellisle F, Thornton SN, Hébel P, Denizeau M, Tahiri M. A study of fluid intake from beverages in a sample of healthy French children, adolescents and adults. Eur J Clin Nutr. 2010;64(4):350-5.

14. Stern D, Piernas C, Barquera S, Rivera JA, Popkin BM. Caloric beverages were major sources of energy among children and adults in Mexico, 1999-2012. J Nutr. 2014;144(6):949-56.

15. Guelinckx I, Iglesia I, Bottin JH, De Miguel-Etayo P, González-Gil EM, SalasSalvadó J, et al. Intake of water and beverages of children and adolescents in 13 countries. Eur J Nutr. 2015;54(Suppl 2):69-79.

16. Coppinger $T$, Jeanes $Y$, Mitchell $M$, Reeves $S$. Beverage consumption and BMI of British schoolchildren aged 9-13 years. Public Health Nutr. 2013;16(7):1244-9.

17. Johnson L, Mander AP, Jones LR, Emmett PM, Jebb SA. Is sugar-sweetened beverage consumption associated with increased fatness in children? Nutr. 2007;23(7-8):557-63.

18. Bates B, Lennox A, Prentice A, Bates C, Page P, Nicholson S, Swan G National Diet and nutrition survey results from years 1, 2, 3 and 4 (combined) of the rolling Programme (2008/2009-2011/2012): a survey carried out on behalf of Public Health England and the Food Standards Agency. 2014.

19. Ministry of Education. School food policy factsheets, UK-England. 2014. https://ec.europa.eu/jrc/sites/default/files/jrc-school-food-policy-factsheetengland_en.pdf. Accessed 13 May 2017.

20. Cole TJ, Lobstein T. Extended international (IOTF) body mass index cut-offs for thinness, overweight and obesity. Pediatr Obes. 2012;7(4):284-94.

21. National Diet and Nutrition Survey (NDNS) consent form. https://www.food. gov.uk/sites/default/files/ndns-appendix-j.pdf . Accessed 13 May 2017.

22. Hagenaars AJM, de Vos K, Zaidi MA. Poverty statistics in the late 1980s: research based on micro-data. Luxembourg: Office for Official Publications of the European Communities; 1994.

23. OECD. OECD framework for statistics on the distribution of household income. Paris: Consumption and Wealth. OECD Publishing; 2013.

24. Food Standards Agency. McCance and Widdowson's the composition of foods, Sixth summary edition. Cambridge: The Royal Society of Chemistry; 2002.

25. McDonald J. Handbook of biological statistics. 1st ed. Baltimore: Sparky House Publishing; 2009

26. Vieux F, Maillot M, Constant F, Drewnowski A. Water and beverage consumption among children aged 4-13 years in France: analyses of INCA 2 (Étude Individuelle Nationale des Consommations Alimentaires 2006-2007) data. Public Health Nutr. 2016;19(13):2305-14.

27. Lioret S, Dubuisson C, Dufour A, Touvier M, Calamassi-Tran G, Maire B, et al. Trends in food intake in French children from 1999 to 2007: results from the INCA (etude Individuelle Nationale des Consommations Alimentaires) dietary surveys. Br J Nutr. 2010;103(4):585-601. 